\title{
Aplikasi Kendali Optimal Untuk Model Persediaan yang Mengalami Kerusakan pada Persediaan dan Perubahan Tingkat Permintaan
}

\author{
Nilwan Andiraja ${ }^{1}$, Dinda Agustina ${ }^{2}$ \\ 1,2 Jurusan Matematika, Fakultas Sains dan Teknologi, UIN Sultan Syarif Kasim Riau \\ Jl. HR. Soebrantas No. 155 Simpang Baru, Panam, Pekanbaru, 28293 \\ Email: nilwanandiraja@uin-suska.ac.id, dindaagustina425@gmail.com,
}

\begin{abstract}
ABSTRAK
Permasalahan kenaikan dan penurunan barang pada persediaan merupakan penelitian yang pernah diteliti sebelumnya oleh Affandi (2015). Tujuan dari penelitian ini untuk mendapatkan persamaan tingkat produksi dan analisa kestabilan tiingkat persediaan barang yang optimal. Oleh karena itu, penelitian ini membahas tentang kendali optimal dari sistem persediaan dengan kasus penurunan barang yang diakibatkan oleh kerusakan dan perubahan permintaan. Untuk mendapatkan tingkat produksi dan analisa tingkat persediaan, pada model ini digunakan teori kendali, Berdasarkan persamaan differensial dinamik dan fungsi tujuan yang diberikan dapat dibentuk persamaan Hamilton dan Lagrange. Kemudian ditentukan produksi dan persamaan tingkat persediaan yang optimal. Fungsi kendali yang telah diperoleh, digunakan untuk menganalisa kestabilan persamaan differensial dinamik. Berdasarkan contoh yang telah diberikan, maka diperoleh bahwa kurva tingkat persediaan menurun dan meningkat pada waktu yang telah ditentukan. Selanjutnya, penelitian ini dapat dikembangkan lebih lanjut dengan merubah tingkat kerusakan dengan eksponensial.
\end{abstract}

Kata Kunci: Kendali Optimal, Kerusakan, Model Persediaan Barang, Persamaan Differensial Dinamik, Perubahan Tingkat Permintaan.

\begin{abstract}
The problem of rising and decreasig goods in inventory is a research that has been previously studied by Affandi (2015). The purposse of this study is to obtain an equation of production levels and an optimal analysis of inventory levels of goods. Therefore, this study discusses the optimal control of the inventory system with the case of a decrease in goods caused by damage and changes in the level of demand. To obtain the level of production and inventory level analysis, the control theory is used in this model. Based on dynamic differential equations and the given objective function, Hamilton and Lagrange Equations can be formed. Then determined the optimal production and inventory level equations. Control functions that have been obtained, are used to analyze the stability of dinamic differential equations. Based on example given, it is found that the inventory level curve decreases and increase at a specified time. Futhermore, this research can be further developed by changing the level of damage exponentially.
\end{abstract}

Keywords:Change in demand level, Damage, Differential equation system, Inventory model, Optimal Control.

\section{Pendahuluan}

Perusahaan yang bergerak dalam bidang perdagangan maupun manufaktur selalu mengandalkan persediaan. Dengan diadakannya persediaan yang terlalu banyak akan menyebabkan perusahaan mengeluarkan biaya perawatan ataupun biaya asuransi. Namun, persediaan yang terlalu sedikit akan menyebabkan kerugian bagi perusahaan, seperti biaya pesan yang meningkat dan berhentinya produksi akibat kekurangan bahan baku dan kehilangan kepercayaan konsumen yang menyebabkan konsumen berpindah ke perusahaan lain.

Ada dua faktor permasalahan yang diteliti dalam merumuskan model persediaan yaitu kerusakan barang dan tingkat permintaan barang. Salah satu permasalahan klasik pada persediaan adalah menyesuaikan perubahan tingkat permintaan konsumen pada sebuah produk. Oleh sebab 
itu, perusahaan tersebut harus membuat perencanaan yang baik dalam memproduksi barang supaya sesuai dengan permintaan. Kerusakan dalam persediaan biasanya terjadi karena lamanya waktu penyimpanan barang. Kerusakan pada produk akan menyebabkan kerugian bagi perusahaan. Oleh sebab itu, kendali optimal pada model persediaan diharapkan mampu menyeimbangkan antara persediaan dan permintaan.

Beberapa penelitian yang terkait pembahasan aplikasi teori kendali pada persediaan dapat dilihat dalam artikelpada [1], [3]dan [9]. Dalam penelitian-penelitian tersebut membahas model matematika dari masalah persediaan yang mengalami penurunan untuk waktu berhingga serta bagaimana menyelesaikan bentuk model persediaan barang tersebut menggunakan teknik kendali optimal, sehingga diperoleh persamaan produksi dan persamaan tingkat persediaan yang optimal. Tapi pada [1] dan [9], pada modelnya persamaan tingkat permintaan barang yang diberikan dalam bentuk persamaan umum sementara pada [2] perubahan tingkat permintaan belum dalam bentuk persamaan kuadrat. Oleh karena itu, pada artikel ini merubah tingkat permintaan pada [1] dengan persamaan kuadrat dan selanjutnya akan dicari persamaan tingkat persediaan barang.

\section{Metode dan Bahan Penelitian}

\section{Model Persediaan Barang}

\section{a. Kendali Optimal pada Masalah Persediaan Barang}

Pembentukan model ini didasarkan pada sistem persediaan dimana ditinjau persediaan saat terjadi peningkatan dan penurunan barang. Di asumsikan bahwa fase pertama dari $t_{0}$ hingga $t_{1}$ untuk tingkat persedian yang meningkat, kemudian fase kedua yaitu $t_{1}$ hinggat $t_{2}$ untuktingkatpersediaan yang menurun.Berikutinidigambarkan model persediaan yang mengalamifaseperubahaninventori.

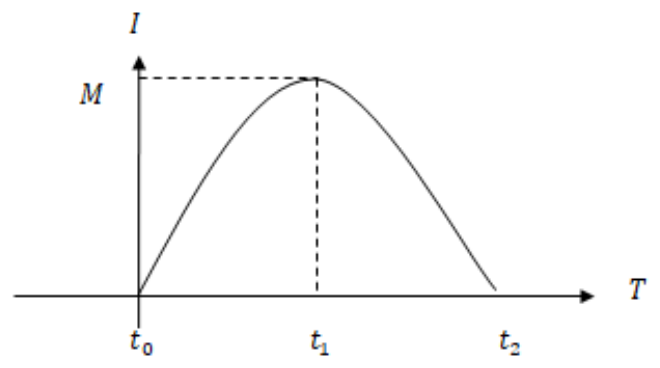

Gambar 1. Model Persediaan denganPerubahanFase

Pada Gambar 1di atas,membahas dua kasus, yaitu kasus model penurunan barang dan model kenaikan barang. Kedua kasus tersebutdapat didefinisikan dalam persamaan differensial dinamik, yaitu:

$$
\dot{I}=\left\{\begin{array}{lr}
P(t)+v(t) I(t), & t \in\left[0, t_{1}\right] \\
P(t)-D(t)+v(t) I(t), & t \in\left[t_{1}, t_{2}\right]
\end{array} .\right.
$$

Dalam penelitian ini, hanya akan dibahas persoalan untuk kasus penurunan barang.Kasus penurunan barang dapat didefinisikan dengan persamaan differensial dinamik [1], yaitu:

$$
\dot{I}=P(t)-D(t)+v(t) I(t) \quad t \in\left[t_{1}, t_{2}\right]
$$

dengan $v(t)=m(t)-\theta(t), P(t) \geq 0$. Kemudian, untuk menjamin tingkat persediaan menurun dari $t_{1}$ hingga $t_{2}$, lebih lanjut Persamaan diferensial dinamik memenuhi:

dengan

$$
P(t)-D(t)+v(t) I(t)>0 \quad t \in\left[t_{1}, t_{2}\right]
$$

$I(t) \quad$ : Tingkat fungsi persediaan.

$P(t) \quad$ : Tingkat fungsiproduksi.

$D(t) \quad$ : Fungsi permintaan.

$I_{0} \quad$ : Tingkat nilai awal persediaan.

$m(t) \quad$ : Rata-rata fungsi kenaikan.

$\theta(t) \quad$ : Rata-rata fungsi kemerosotan. 
$\mathrm{v}(\mathrm{t}) \quad$ :Selisih dan rata-rata fungsi kenaikan dan penurunan

Dengan fungsi tujuan dari model persediaan barang yang mengalami penurunan adalah sebagai berikut:

dengan

$$
J=\frac{1}{2} \int_{0}^{t}\left\{h[I(t)-\hat{I}]^{2}+K[P(t)-\hat{P}]^{2}\right\} d t
$$

$\hat{P} \quad$ : Tingkat produksi tujuan

$\hat{I} \quad$ : Tingkat persediaan tujuan

$h \quad$ : Koefisien biaya penyimpanan

$K \quad$ : Koefisien biaya produksi

Dengan diketahui persamaan diferensial dinamik dan fungsi tujuan, maka menurut [6] masalah persediaan barang dapat juga dipandang sebagai bentuk model kendali optimal.

Selanjutnya, untuk mencari tingkat produksi yang optimal, persamaan diferensial dinamik yang ada diubah kebentuk persamaan Hamilton [1]. Selanjutnya, berdasarkan [4] dibentuk persamaan Hamilton, pada persoalan model persediaan barang, persamaan Hamilton sebagai berikut:

dengan

$$
H=\frac{1}{2}\left[h(I-\hat{I})^{2}+K(P-\hat{P})^{2}\right]+\lambda g,
$$

danfungsi Lagrange adalah sebagai berikut:

$$
g=P(t)-D(t)+v(t) I(t) \quad t \in\left[t_{1}, t_{2}\right]
$$

$$
L=\frac{1}{2}\left[h(I-\hat{I})^{2}+K(P-\hat{P})^{2}\right]+(\lambda-\mu) g, \quad t \in\left[t_{1}, t_{2}\right]
$$

Menurut [8] syarat yangdiperlukan untuk kondisi optimalyaitu,

$$
\begin{aligned}
& H p=0 \\
& L_{I}=-\dot{\lambda} \\
& L_{p}=0 \\
& \mu \geq 0, \mu g \geq 0 .
\end{aligned}
$$

Dengan $H p=0$ merupakan menentukan titik tingkat produksi yang optimal sekaligus sebagai titik stasioner. Titik stasioner dapat diperoleh dengan turunan pertama yang dapat dilihat pada [7].

\section{b. Permintaan}

Menurut [2], permintaan adalah berbagai jumlah barang yang diminta akan suatu barang pada berbagai tingkat harga. Jika harga suatu barang naik, maka jumlah barang yang dimintaakan berkurang. Sebaliknya jika harga suatu barang turun, maka jumlah barang yang dimintaakan bertambah. Selanjutnya, menurut [2], bentuk umum dari fungsi permintaan kuadrat yang berubah terhadap waktu adalah,

$$
D=a+b t+c t^{2}
$$

Dengan $a, b, c$ merupakan konstanta dengan waktu $t$.

Adapun tahapan-tahapan yang akan dilakukan adalah sebagai berikut:

1. Diketahui fungsi differensial dinamik sebagai berikut:

$$
\dot{I}=P(t)-\left(a+b t+c t^{2}\right)-\theta(t) I(t), \quad t \in\left[t_{1}, t_{2}\right]
$$

dengan fungsi tujuan sebagai berikut:

$$
J=\frac{1}{2} \int_{0}^{t}\left\{h[I(t)-\hat{I}]^{2}+K[P(t)-\hat{P}]^{2}\right\} d t
$$

2. Didefinisikan persamaan Hamilton sebagai berikut:

$$
H=\frac{1}{2}\left[h(I-\hat{I})^{2}+K(P-\hat{P})^{2}\right]+\lambda g
$$

3. Kemudian, didefinisikan persamaan Lagrange sebagai berikut: 


$$
L=\frac{1}{2}\left[h(I-\hat{I})^{2}+K(P-\widehat{P})^{2}\right]+(\lambda-\mu) g
$$

4. Berdasarkan langkah pada no 2 dan 3 akan dibentuk kondisi yang optimal pada persediaan barang yang mengalami penurunan pada persediaan yang diakibatkan oleh kerusakan dan perubahan tingkat permintaan dengan syarat yang diberikanpada [8] sebagai berikut: $\frac{\partial H}{\partial P}=0, \frac{\partial L}{\partial I}=-\dot{\lambda}, \frac{\partial L}{\partial P}=0$

5. Dari langkah yang terdapat pada no 4 diperoleh solusi persamaan differensial untuk persediaan barang yang mengalami penurunan yang disebabkan oleh kerusakan dan perubahan tingkat permintaan.

6. Selanjutnya, solusi tingkat persediaan yang didapat pada langkah no 5 akan dianalisis kestabilannya.

\section{Hasil dan Pembahasan}

Pada bagian ini akan dibahas tentang kendali optimal pada model persediaan barang dengan tingkat permintaan fungsi kuadrat untuk waktu kontinu dan menyelesaikan dengan menggunakan teknik kendali optimal.

\section{Kendali Optimal pada Masalah Persediaan Barang}

Didefinisikan differensial dinamik untuk kasus persediaan barang yang mengalami penurunan adalah sebagai berikut:

$$
\dot{I}=P(t)-\left(a+b t+c t^{2}\right)-\theta(t) I(t), \quad t \in\left[t_{1}, t_{2}\right]
$$

Selanjutnya, diberikan fungsi tujuan dengan kasus penurunan barang adalah sebagai berikut:

$$
J=\frac{1}{2} \int_{0}^{t}\left\{h[I(t)-\hat{I}]^{2}+K[P(t)-\hat{P}]^{2}\right\} d t
$$

Kemudian, untukmenyederhanaknpenulisanselanjutnya dinotasikan $P(t)=P$ dan $I(t)=I$. Persamaan Hamilton didefinisikan sebagai berikut:

$$
H=\frac{1}{2}\left[h(I-\hat{I})^{2}+K(P-\hat{P})^{2}\right]+\lambda g
$$

dan persamaan Lagrange didefinisikan sebagai berikut:

$$
L=\frac{1}{2}\left[h(I-\hat{I})^{2}+K(P-\widehat{P})^{2}\right]+(\lambda-\mu) g
$$

Syarat kondisi optimal pada persediaan barang yang mengalami penurunan diberikan sebagai berikut:

Berdasarkan Persamaan (5) diperoleh:

$$
\begin{aligned}
& \frac{\partial H}{\partial P}=0 \\
& \frac{\partial L}{\partial I}=-\dot{\lambda} \\
& \frac{\partial L}{\partial P}=0
\end{aligned}
$$

$$
\begin{aligned}
\frac{\partial H}{\partial P} & =\frac{1}{2}\left[h(I-\hat{I})^{2}+K(P-\hat{P})^{2}\right]+\lambda\left(P-\left(a+b t+c t^{2}\right)-\theta I\right)=0 \\
P & =\hat{P}-\frac{\lambda}{K}
\end{aligned}
$$

Berdasarkan Persamaan (6) diperoleh:

$$
\begin{aligned}
-\dot{\lambda} & =\frac{1}{2}\left[h(I-\hat{I})^{2}+K(P-\widehat{P})^{2}\right]+(\lambda-\mu)\left(P-\left(a+b t+c t^{2}\right)-\theta I\right) \\
\dot{\lambda} & =-h(I-\hat{I})+(\lambda-\mu) \theta
\end{aligned}
$$

Berdasarkan Persamaan (7) diperoleh:

$$
0=\frac{1}{2}\left[h(I-\hat{I})^{2}+K(P-\widehat{P})^{2}\right]+(\lambda-\mu)\left(P-\left(a+b t+c t^{2}\right)-\theta I\right)
$$


$0=K(P-\widehat{P})+(\lambda-\mu)$

Kemudian disubstitusikan Persamaan (8) ke Persamaan (1) maka diperoleh:

$$
\dot{I}=\left(\widehat{P}-\frac{\lambda}{K}\right)-\left(a+b t+c t^{2}\right)-\theta I
$$

dengan turunan pada Persamaan (11) maka diperoleh:

$$
\ddot{I}=-\frac{\dot{\lambda}}{K}-b-2 c t-\dot{\theta} I-\theta \dot{I}
$$

selanjutnya disubstitusikan Persamaan (9) dan Persamaan (11) ke Persamaan (12) diperoleh:

$$
\begin{aligned}
\ddot{I}= & -\frac{(-h(I-\widehat{I})+(\lambda-\mu) \theta)}{K}-b-2 c t-\dot{\theta} I \\
& -\theta\left(\left(\widehat{P}-\frac{\lambda}{K}\right)-\left(\mathrm{a}+\mathrm{b} t+\mathrm{c} t^{2}\right)-\theta I\right)
\end{aligned}
$$

dan berdasarkan Persamaan (10) maka $-K(P-\hat{P})=(\lambda-\mu)$, sehingga

$$
\ddot{I}=\frac{h(I-\hat{I})}{K}-\left(\frac{-K(P-\hat{P}) \theta}{K}\right)-(b+2 c t)-\dot{\theta} I-\theta\left(\hat{P}-\frac{\lambda}{K}-\left(a+b t+c t^{2}\right)-\theta I\right)
$$

Berdasarkan Persamaan (8) maka $(P-\hat{P})=-\frac{\lambda}{K}$, sehingga

$$
\ddot{I}-\left(\frac{h}{K}-\dot{\theta}+(\theta)^{2}\right) I=\theta c t^{2}+(\theta b-2 c) t-\frac{h}{K} \hat{I}-\theta \hat{P}+\theta a-b
$$

Selanjutnya untuk mendapatkan solusi dari Persamaan (14) tersebut maka akan diamati dua kasus dalam bentuk solusi ekspilisit. Dua kasus yang akan diselesaikan dalam bentuk solusi ekspilisit adalah sebagai berikut:

\section{A. Kasus $\hat{I}$ dan $\boldsymbol{\theta}$ adalah konstan}

Kasus $\hat{I}$ dan $\theta$ dalam bentuk konstan dapat dilihat dalam persamaan differensial pada Persamaan (14) akan diperoleh sebagai berikut:

$$
\ddot{I}-\left(\frac{h}{K}-\dot{\theta}+(\theta)^{2}\right) I=\theta c t^{2}+(\theta b-2 c) t-\frac{h}{K} \hat{I}-\theta \hat{P}+\theta a-b
$$

dengan Persamaan (15) merupakan persamaan differensial orde dua nonhomogen. Langkah pertama yang harus dilakukan dalam penyelesaian Persamaan (15) dapat dilihat pada [10] yaitu menentukan terlebih dahulu penyelesaian umum persamaan homogen. Dari persamaan homogen tersebut diperoleh persamaan karakteristik sebagai berikut:

$$
r^{2}-\left(\frac{h}{K}-\dot{\theta}+(\theta)^{2}\right)=0
$$

selanjutnya, akar-akar persamaan yang diperoleh dari persamaan tersebut $r_{1}=\sqrt{\left(\frac{h}{K}-\dot{\theta}+(\theta)^{2}\right)}=r$ dan $r_{2}=-\sqrt{\left(\frac{h}{K}-\dot{\theta}+(\theta)^{2}\right)}=-r$ sehingga solusi dari dari Persamaan (15) adalah

$$
I(t)=c_{1} e^{r t}+c_{2} e^{-r t}+I_{c}(t)
$$

dimana $I_{c}(t)$ merupakan solusi untuk persamaan nonhomogen dari Persamaan (15). Kemudian, diperoleh $\quad I_{c}(t)=\frac{-\theta c t^{2}-(\theta b-2 c) t+\left(\frac{h}{K} \hat{I}+\theta\left(\hat{P}-a-\frac{2 c}{\left(\frac{h}{\bar{K}}-\dot{\theta}+(\theta)^{2}\right)}\right)+b\right)}{\frac{h}{\bar{K}}-\dot{\theta}+(\theta)^{2}} . \quad$ Selanjutnya, untuk menentukan $P(t)$ yaitu dengan menggunakan kondisi $I\left(t_{1}\right)=M \operatorname{dan} \lambda\left(t_{2}\right)=0$ pada Persamaan (17) akan diperoleh sebagai berikut:

a. Untuk $t=t_{1}$ diperoleh,

b. Untuk $t=t_{2}$ diperoleh

$$
M=c_{1} e^{r t_{1}}+c_{2} e^{-r t_{1}}+I_{c}\left(t_{1}\right)
$$




$$
0=K\left(c_{1}(-r-\theta) e^{r t_{2}}+c_{2}(r-\theta) e^{-r t_{2}}-\dot{I}_{c}\left(t_{2}\right)+\hat{P}-\left(a+b t+c t^{2}\right)-\theta I_{c}\left(t_{2}\right)\right)
$$

Nilai $c_{1}$ dan $c_{2}$ dapat diselesaikan sebagai berikut:

$$
\begin{aligned}
& \boldsymbol{A}=\boldsymbol{B} \boldsymbol{x}+\boldsymbol{C} \\
& {\left[\begin{array}{c}
M \\
0
\end{array}\right]=\left[\begin{array}{cc}
e^{r t_{1}} & e^{-r t_{1}} \\
(-r-\theta) e^{r t_{2}} & (r-\theta) e^{-r t_{2}}
\end{array}\right]\left[\begin{array}{l}
c_{1} \\
c_{2}
\end{array}\right]+\left[\begin{array}{c}
I_{c}(t) \\
-\dot{I}_{c}\left(t_{2}\right)+\hat{P}-\left(a+b t+c t^{2}\right)-\theta I_{c}\left(t_{2}\right)
\end{array}\right]}
\end{aligned}
$$

maka $\boldsymbol{X}=\boldsymbol{B}^{-\mathbf{1}}(\boldsymbol{A}-\boldsymbol{C})$, sehingga diperoleh:

dan

$$
c_{1}=\frac{(r-\theta) e^{-r t_{2}}\left(M-I_{c}\left(t_{1}\right)\right)-e^{-r t_{1}}\left(\dot{I}_{c}\left(t_{2}\right)-\hat{P}+\left(a+b t+c t^{2}\right)+\theta I_{c}\left(t_{2}\right)\right)}{\left(e^{r t_{1}}\right)\left((r-\theta) e^{-r t_{2}}\right)-\left(e^{-r t_{1}}\right)\left((-r-\theta) e^{r t_{2}}\right)}
$$

$$
c_{2}=\frac{(r+\theta) e^{r t_{2}}\left(M-I_{c}\left(t_{1}\right)\right)+\left(e^{r t_{1}}\right)\left(\dot{I}_{c}\left(t_{2}\right)-\hat{P}+\left(a+b t+c t^{2}\right)+\theta I_{c}\left(t_{2}\right)\right)}{\left(e^{r t_{1}}\right)\left((r-\theta) e^{-r t_{2}}\right)-\left(e^{-r t_{1}}\right)\left((-r-\theta) e^{r t_{2}}\right)}
$$

Berdasarkan Persamaan (11) dan Persamaan (17) diperoleh sebagai berikut:

$$
\begin{aligned}
& \lambda=K\left(-\dot{I}-\left(a+b t+c t^{2}\right)-\theta I+\hat{P}\right) \\
& \lambda=K\left(c_{1}(-r-\theta) e^{r t}+c_{2}(r-\theta) e^{-r t}-\dot{I}_{c}(t)+\hat{P}-\left(a+b t+c t^{2}\right)-\theta I_{c}(t)\right)
\end{aligned}
$$

sehingga dari Persamaan (18) dapat disubstitusikan ke Persamaan (8) dan diperoleh sebagai berikut:

$P=\hat{P}-\left(c_{1}(-r-\theta) e^{r t}+c_{2}(r-\theta) e^{-r t}-\dot{I}_{c}(t)+\hat{P}-\left(a+b t+c t^{2}\right)-\theta I_{c}(t)\right)$

B. $\quad \operatorname{Kasus} \frac{h}{K}-\dot{\theta}+\theta^{2}$ adalah konstan

Diasumsikan:

$$
\frac{h}{K}-\dot{\theta}+\theta^{2}=k_{1}^{2}
$$

sehingga Persamaan (15) akan diperoleh:

$\ddot{I}-\left(k_{1}^{2}\right) I=-\frac{h}{K} \hat{I}-\theta\left(\hat{P}-a-b t-c t^{2}\right)-b-2 c t t \in\left[t_{1}, t_{2}\right]$

maka akan diperoleh persamaan differensial orde dua nonhomogen. Kemudian, untuk menyelesaikan Persamaan (20) perlu menghitung $k_{1}{ }^{2}-\frac{h}{K}=a^{2}$ terlebih dahulu untuk mendapatkan solusi Persamaan (20), maka penyelesaian Persamaan (20) adalah $\frac{d \theta}{-a^{2}+\theta^{2}}=$ $d t$, bentuk tersebut dapat diselesaikan dengan mengintegralkan kedua ruas sehingga diperoleh $\theta=\frac{a\left(-e^{2 a t}-1\right)}{\left(e^{2 a t}-1\right)}$. Kemudian dengan mensubstitusikan $\theta$ ke dalam Persamaan (21) diperoleh :

$\ddot{I}-\left(k_{1}^{2}\right) I=-\frac{h \hat{I}}{K}-\frac{a\left(-e^{2 a t}-1\right)}{\left(e^{2 a t}-1\right)}\left(\hat{P}-\left(a+b t+c t^{2}\right)\right)-(b+2 c t)$

dengan Persamaan (22) merupakan persamaan differensial orde dua nonhomogen. Langkah pertama yang dilakukan untuk menyelesaikan Persamaan (22) adalah dengan menentukan terlebih dahulu penyelesaian umum persamaan homogen sehingga akan diperoleh persamaan karakteristiknya sebagai berikut:

$$
\ddot{I}-\left(k_{1}^{2}\right)=0
$$


dan akar-akar persamaan yang diperoleh $r_{1}=k_{1}$ dan $r_{2}=-k_{1}$ sehingga solusi dari Persamaan (23) yaitu:

$$
I(t)=c_{1} e^{k_{1} t}+c_{2} e^{-k_{1} t}+Q(t)
$$

dimana $I(t)$ merupakan solusi untuk persamaan nonhomogen dari Persamaan (22). Kemudian diperoleh:

$$
Q(t)=\theta_{1} e^{k_{1} t}+\theta_{2} e^{-k_{1} t}
$$

dengan $\theta_{1}$ dan $\theta_{2}$ merupakan anti turunan dari $\dot{\theta}_{1} \operatorname{dan} \dot{\theta}_{2}$.

Selanjutnya, untuk menentukan $P(t)$ dengan menggunakan kondisi $I\left(t_{1}\right)=$ $M \operatorname{dan} \lambda\left(t_{2}\right)=0$ maka akan diperoleh sebagai berikut:

a. $\operatorname{Untuk} I\left(t_{1}\right)=M$ diperoleh $I(t)=\left(c_{1}+\theta_{1}\right) e^{k_{1} t_{1}}+\left(c_{1}+\theta_{2}\right) e^{-k_{1} t_{1}}+\frac{h}{K k_{1}{ }^{2}} \hat{I}$

b. Untuk $\lambda\left(t_{2}\right)=0$ diperoleh

$$
\lambda\left(t_{2}\right)=K\left(\begin{array}{l}
\left(\left(-\theta-k_{1}\right)\left(c_{1}+\theta_{1}\right) e^{k_{1} t_{2}}\right)+\left(\left(-\theta+k_{1}\right)\left(c_{2}+\theta_{2}\right) e^{-k_{1} t_{2}}\right)-\dot{\theta}_{1} e^{k_{1} t_{2}}-\dot{\theta}_{2} e^{-k_{1} t_{2}} \\
-\left(a+b t+c t^{2}\right)-\theta \frac{h}{K k_{1}{ }^{2}}+\hat{P}
\end{array}\right)
$$

Nilai $c_{1}$ dan $c_{2}$ dapat diselesaikan sebagai berikut:

$$
\begin{aligned}
& {\left[\begin{array}{c}
M \\
0
\end{array}\right]=\left[\begin{array}{cc}
e^{k_{1} t_{1}} & e^{-k_{1} t_{1}} \\
\left(-\theta-k_{1}\right) e^{k_{1} t_{2}} & \left(-\theta+k_{1}\right) e^{-k_{1} t_{2}}
\end{array}\right]\left[\begin{array}{l}
c_{1} \\
c_{2}
\end{array}\right]+} \\
& {\left[\begin{array}{c}
\theta_{1} e^{k_{1} t_{1}}+\theta_{2} e^{-k_{1} t_{1}}+\frac{h}{K k_{1}^{2}} \hat{I} \\
\left(\left(-\theta-k_{1}\right) \theta_{1} e^{k_{1} t_{2}}\right)+\left(\left(-\theta+k_{1}\right) \theta_{2} e^{-k_{1} t_{2}}\right)-\dot{\theta}_{1} e^{k_{1} t_{2}}-\dot{\theta}_{2} e^{-k_{1} t_{2}} \\
-\left(a+b t+c t^{2}\right)-\theta \frac{h}{K k_{1}^{2}}+\hat{P}
\end{array}\right]}
\end{aligned}
$$

Maka $=\boldsymbol{B}^{-\mathbf{1}}(\boldsymbol{A}-\boldsymbol{C})$, sehingga diperoleh:

$$
\begin{aligned}
& \left(\left(-\theta+k_{1}\right) e^{-k_{1} t_{2}}\right)\left(M-\left(\theta_{1} e^{k_{1} t_{1}}+\theta_{2} e^{-k_{1} t_{1}}+\frac{h}{K k_{1}^{2}} \hat{I}\right)\right)+\left(e^{-k_{1} t_{1}}\right) \\
& c_{1}=\frac{\left(\begin{array}{l}
\left(\left(-\theta-k_{1}\right) \theta_{1} e^{k_{1} t_{2}}\right)+\left(\left(-\theta+k_{1}\right) \theta_{2} e^{-k_{1} t_{2}}\right)-\dot{\theta}_{1} e^{k_{1} t_{2}}-\dot{\theta}_{2} e^{-k_{1} t_{2}} \\
-\left(a+b t+c t^{2}\right)-\theta \frac{h}{K k_{1}^{2}}+\hat{P}
\end{array}\right)}{\left(e^{k_{1} t_{1}}\right)\left(\left(-\theta+k_{1}\right) e^{-k_{1} t_{2}}\right)-\left(e^{-k_{1} t_{1}}\right)\left(\left(-\theta-k_{1}\right) e^{k_{1} t_{2}}\right)}
\end{aligned}
$$

dan 


$$
\begin{aligned}
& \left(-\left(-\theta-k_{1}\right) e^{k_{1} t_{2}}\right)\left(M-\left(\theta_{1} e^{k_{1} t_{1}}+\theta_{2} e^{-k_{1} t_{1}}+\frac{h}{K k_{1}^{2}} \hat{I}\right)\right)-\left(e^{k_{1} t_{1}}\right) \\
& c_{2}=\frac{\left(\begin{array}{l}
\left(\left(-\theta-k_{1}\right) \theta_{1} e^{k_{1} t_{2}}\right)+\left(\left(-\theta+k_{1}\right) \theta_{2} e^{-k_{1} t_{2}}\right)-\dot{\theta}_{1} e^{k_{1} t_{2}}-\dot{\theta}_{2} e^{-k_{1} t_{2}} \\
-\left(a+b t+c t^{2}\right)-\theta \frac{h}{K k_{1}^{2}}+\hat{P}
\end{array}\right)}{\left(e^{k_{1} t_{1}}\right)\left(\left(-\theta+k_{1}\right) e^{-k_{1} t_{2}}\right)-\left(e^{-k_{1} t_{1}}\right)\left(\left(-\theta-k_{1}\right) e^{k_{1} t_{2}}\right)}
\end{aligned}
$$

Berdasarkan Persamaan (11) dan Persamaan (24) diperoleh sebagai berikut:

$$
\begin{aligned}
& \lambda=K\left(-\dot{I}-\left(a+b t+c t^{2}\right)-\theta I+\hat{P}\right) \\
& \lambda=K\left(\begin{array}{l}
\left(\left(-\theta-k_{1}\right)\left(c_{1}+\theta_{1}\right) e^{k_{1} t}\right)+\left(\left(-\theta+k_{1}\right)\left(c_{2}+\theta_{2}\right) e^{-k_{1} t}\right)-\dot{\theta}_{1} e^{k_{1} t}-\dot{\theta}_{2} e^{-k_{1} t} \\
-\left(a+b t+c t^{2}\right)-\theta \frac{h}{K k_{1}^{2}}+\hat{P}
\end{array}\right)
\end{aligned}
$$

Sehingga dari Persamaan (25) dapat disubstitusikan ke Persamaan (8) dan diperoleh persamaan tingkat produksi,

$$
P=\hat{P}-\left(\begin{array}{l}
\left(\left(-\theta-k_{1}\right)\left(c_{1}+\theta_{1}\right) e^{k_{1} t}\right)+\left(\left(-\theta+k_{1}\right)\left(c_{2}+\theta_{2}\right) e^{-k_{1} t}\right)-\dot{\theta}_{1} e^{k_{1} t}-\dot{\theta}_{2} e^{-k_{1} t} \\
-\left(a+b t+c t^{2}\right)-\theta \frac{h}{K k_{1}^{2}}+\hat{P}
\end{array}\right)
$$

\section{Simulasi Parameter Model}

\section{Contoh:}

Selanjutnya akan diberikan simulasi dengan parameter untuk tingkat persediaan.

Berdasarkan jurnal Pardi Affandi (2015) dan jurnal Nur Azizah (2018), diketahui $\hat{I}=25, \hat{P}=$ $19, t_{2}=5, M=25, h=1.5, a=1, b=3, c=1, K=60$ dan tingkat kerusakan sebesar 4. Tentukan nilai optimal tingkat persediaan $(I(t))$ dan analisis kestabilannya pada saat $t \in[0,11]$.

\section{Penyelesaian:}

$$
\begin{aligned}
& r=4.003123780 \\
& -r=-4.003123780 \\
& \dot{I}_{c}(t)=-0,4992 t-0,6240
\end{aligned}
$$

Kemudian disubstitusikan nilai-nilai diatas ke $c_{1}, c_{2}$ dan Persamaan (17). Nilai solusi dari Persamaan (17) untuk $t \rightarrow 11$ dengan menggunakan [5] dan bantuan Program Maple diperoleh pada grafik, 


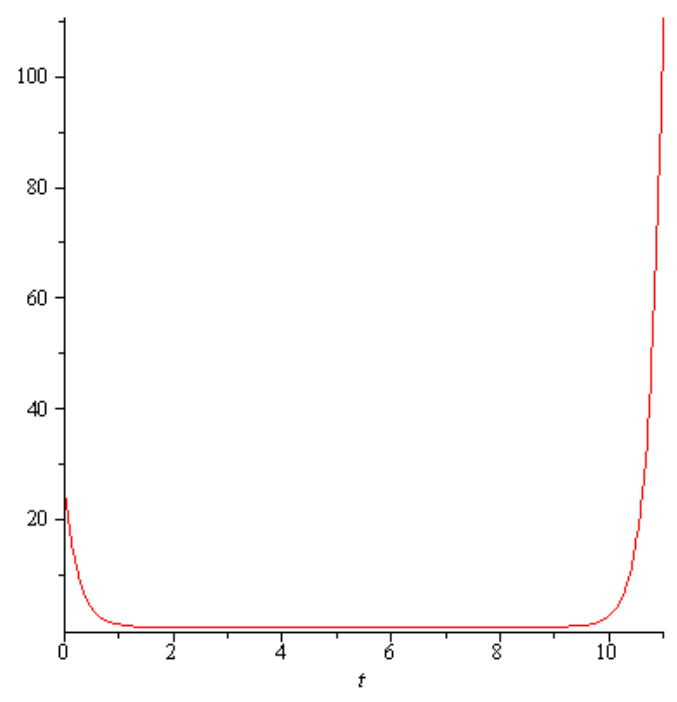

Gambar 2. GrafikI $(t)$ untuk $t \rightarrow 11$

Berdasarkan Gambar 2, tampak bahwa untuk $t \rightarrow 2$ diperoleh nilai tingkat persediaan $I(t)$ menurun stabil dan kurva menuju 0 . Dalam hal ini berarti perusahaan mengalami penurunan yang disebabkan kerusakan dan permintaan. Kemudian, perusahaan melalukan produksi secara terusmenerus sehingga persediaan kembali meningkat dan perusahaan akan selalu dapat memenuhi permintaan konsumen.

\section{Kesimpulan}

Berdasarkan uraian yang telah dijelaskan pada pembahasan maka diperoleh analisa kestabilannya yang didapat dari grafik adalah tingkat persediaan $I(t)$ menurun stabil dan kurva menuju 0. Dalam hal ini berarti perusahaan mengalami penurunan yang disebabkan kerusakan dan permintaan. Kemudian, perusahaan melalukan produksi secara terus-menerus sehingga persediaan kembali meningkat dan perusahaan akan selalu dapat memenuhi permintaan konsumen.

Artikel ini memaparkan tentang model persediaan barang pada kerusakan dan perubahan tingkat permintaan dan menyelesaikannya dengan menggunakan teknik kendali optimal. Pada penulisan artikel ini diharapkan bagi pembaca yang tertarik dengan penelitian ini untuk dapat mengembangkan ini dalam bentuk eksponensial.

\section{Daftar Pustaka}

[1] Affandi, Pardi, Faisal, dan Y. Yulida. 2015. Kendali Optimal dari Sistem Inventori dengan Peningkatan dan Penurunan Barang. Jurnal MIPA UNLAM,38 (1), (2015). 79-88.

[2] Assauri, Sofjan. Matematika Ekonomi, Rajawali Press, Jakarta, 2002.

[3] Azizah, N. Analisis Model EOQ dengan Adanya Kerusakan Barang pada Persediaan dan Perubahan Tingkat Permintaan. Jurnal Matriks, 1(1), 2018.

[4] Lewis, F.L. Optimal Control. John Wiley \& Sons, Inc, Toronto, 1995.

[5] Muhaijir, M. Nizam. Persamaan Diferensial Biasa dengan MAPLE. Pekanbaru. 2018.

[6] Olsder, GJ. Mathematical Sistem Theory. University of Techonology, Delft. 1994.

[7] Purcell, E. J danVarbeg, D. Kalkulus dan Geometri Analitis Jilid 1 Edisi Kelima.: Erlangga, Jakarta, 2005. 
Jurnal Sains Matematika dan Statistika, Vol. 6, No. 2, Juli 2020

ISSN 2460-4542, e-ISSN 2615-8663

[8] Sethi, Suresh P, dan Thomson, Gerald L., Optimal Control Theory, Springer, New York, 2006

[9] Tadj, L dkk. Optimal Control of Inventory System with Ameliorating and Deterioting Items. Applied Items, 10, 2008. 243-245

[10] Xie, Wei Chau. Differential Equations for Engineers. University of Waterloo Cambridge : New York. 2010. 